
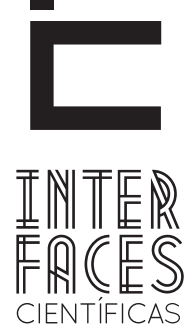

EDUCAÇÃO

\title{
FAZER-SE PROFESSORA PELOS SABERES ESCOLARES DO CURSO NORMAL EM ESTÂNCIA/SE: ENTRE REFORMAS E RESISTÊNCIAS ${ }^{1}$
}

Rony Rei do Nascimento Silva ${ }^{2}$
Laísa Dias Santos ${ }^{3}$

\section{RESUMO}

Este artigo tem como objeto de estudo as memórias escolares das professoras Eleonora Leite Pereira e Cordélia do Nascimento Costa, ambas com 82 anos. 0 ponto em comum partilhado entre elas é o fato de terem sido alunas do Colégio Sagrado Coração de Jesus, localizado no município de Estância, estado de Sergipe. Assim, pretende-se compreender como se constituiu uma "cultura escolar", Julia (2001) e, consequentemente, a produção de um “habitus pedagógico”, Teive (2008) a partir da reforma educacional por decreto $n^{0} 867$ de 11 de março de 1924. 0 referencial teórico adotado foi o da história cultural, segundo Pesavento (2005) e o recurso da metodologia da história oral, segundo Alberti (2004). Conclui-se que para além da reforma educacional, o modo de ser e fazer-se professora ocorre por meio dos mecanismos de resistência que, por sua vez, dão um novo sentido à história da educação.

\section{PALAVRAS-CHAVE}

Reforma Educacional. Habitus Pedagógico. Memória. 


\section{ABSTRACT}

This article has as its object of study the school memories of the teachers Eleonora Leite Pereira and Cordelia do Nascimento Costa, both 82 years old. The common thread shared among them is the fact that they were students of the Sagrado Coração de Jesus School, located in the municipality of Estancia, Sergipe. Thus, the aim is to understand how to set up a "school culture", Julia (2001) and consequently the production of a "pedagogical habitus", Teive (2008) from educational reform by decree No. 867 of March 11, 1924. The theoretical framework adopted is that of cultural history, according to Pesavento (2005) and the use of oral history methodology, according to Alberti (2004). We conclude that in addition to educational reform, how to be and do as a teacher occurs through the mechanisms of resistance that, in turn, give new meaning to the history of education.

\section{KEYWORDS:}

Educational Reform. Pedagogical Habitus. Memory.

\section{RESUMEN}

Este artículo tiene como objeto de estudio los recuerdos escolares de las maestras Eleonora Leite Pereira y Cordelia do Nascimento Costa, ambas con 82 años. El hilo conductor entre ellas es el hecho de que fueron estudiantes del Colegio Sagrado Corazón de Jesús , ubicado en el municipio de Estancia, estado de Sergipe. Por lo tanto, el objetivo es entender cómo se creó una "cultura escolar", Julia (2001) y, en consecuencia la producción de una " habitus pedagógico", Teive (2008) apartir de la reforma de la educación por el decreto ${ }^{\circ}{ }^{\circ}$ 867 del 11 de marzo de 1924. El marco teórico adoptado fue el de la historia cultural, de acuerdo con Pesavento (2005) y el uso de la metodología de la historia oral, de acuerdo con Alberti (2004). Llegamos a la conclusión que, además de la reforma de la educación, la manera de ser y de tornarse un maestro ocurre a través de mecanismos de resistencia que, a su vez, dan un nuevo significado a la historia de la educación.

\section{PALABRAS CLAVE:}

Reforma Educativa. Habitus Pedagógico. Recuerdos.

\section{INTRODUÇ̄̃O}

\begin{abstract}
Cada um conta a sua história de sua maneira, os valores são de quem conta. [...] Eu digo por ter vivido muito, pois tive a felicidade de ver vários aspectos da educação em diferentes tempos. (Eleonora Leite Pereira).
\end{abstract}

Os versos da epígrafe acima foram pronunciados por Eleonora Leite Pereira, de 82 anos, filha de João dos Santos Pereira e Elisia Leite Pereira, residente no município de Estância interior de Sergipe. 0 que compomos textualmente é uma ex- normalista e hoje professora aposentada que ingressou no Colégio Sagrado Coração de Jesus aos sete anos de idade, onde cursou o primário (1938-1942), logo após prestou exame de admissão e ingressou no curso normal na mesma instituição de ensino (1942-1947).

A partir daí, com apenas 17 anos inicia sua carreira na docência. A fim de aprimorar seus conhecimentos ingressou na Escola Técnica de Comércio de Estância, onde se formou técnica em contabilidade (1951-1953). Lecionou a disciplina de Matemática, por um longo período de sua carreira na rede estadual e municipal de ensino, a exemplo, da Escola Técnica de Comércio, bem como em colégios particulares do município de Estância, como o Serviço Social da Indústria (SESI), Colégio Dom Quirino, Colégio Sagrado 
Coração de Jesus, Instituto Diocesano, entre outros. Depois de 48 anos dedicados ao ensino da Matemática, se aposentou oficialmente no ano de 1997. Como prova da representatividade local, a Escola Municipal Professora Eleonora Leite Pereira, recebeu seu nome em homenagem.

Cordélia Nascimento Costa, de 82 anos, filha de João Nascimento Filho e Núbia Lima do Nascimento, ingressou na antiga Escola Isolada Francisco Camerino, quando tinha apenas cinco anos de idade (19351936). Logo em seguida ingressou no Colégio Sagrado Coração de Jesus, onde cursou o primário (1937-1940). Sua aprovação no exame de admissão, no ano de 1941, the possibilitou a entrada no curso normal na mesma instituição de ensino (1941-1946). Com o diploma de professora, nossa personagem dá inicio a sua carreira profissional. Foi nomeada para o cargo de professora primária no Colégio Estadual Gumercindo Bessa, bem como professora da disciplina Geografia da Escola Técnica de Comércio (1951-1961). No período entre 19641965 foi primeira dama do município, casada com o ex-prefeito Alizir Cardoso Costa.

Assumiu a direção da Escola Nossa Senhora de Guadalupe (1965-1970). Foi delegada da Diretoria Regional- DR-I (1970-1974), foi secretaria de educação do município de Estância (1975-1980), período em que cursou Estudos Sociais pela Universidade Federal de Sergipe e em seguida cursou Pedagogia pela Faculdade Pio Décimo na década de 1980. Assumiu a direção do SESI (1981-1990). Aposentou-se no inicio da década de 1990. Hoje a Escola Municipal Professora Cordélia Nascimento Costa, leva seu nome em sua homenagem.

0 presente artigo constitui-se em um escoadouro de narrativas do tempo presente, que traz consigo vozes e silêncios, que muito dizem sobre as configurações educacionais no Estado de Sergipe, no inicio do século XX. Os perfis biográficos acima citados escondem memórias e esquecimentos, referenciadas no cotidiano escolar vivido pelas professoras. Vale ressaltar que, embora suas narrativas não tragam diretamente lembranças da reforma educacional, promulgada pelo decreto de $n^{0} 867$ de 11 de março de 1924, suas experiências escolares muito dizem sobre os efeitos reformistas no curso normal em Estância.

Para alcançar o objetivo, nos propusemos a atentar para as seguintes questões: Quais os efeitos da reforma educacional no 867 no curso normal em Estância? Como se produziu uma cultura escolar e um habitus pedagógico no tensionamento e hibridização entre reforma e resistência? De que modo às memórias escolares pertencentes às entrevistadas, traduzem o ser e fazer-se professora? Como se compuseram educadoras primárias pelos saberes, métodos, programas e disciplinas do curso normal? Quais os pontos de similitudes e diferenças de suas reminiscências escolares?

Para obtermos as respostas para tais questões, imergirmos nos decretos, leis e discursos dos reformadores que regulamentavam o sistema educacional do Estado de Sergipe no início do século XX, bem como nas narrativas que revelam as práticas sociais das entrevistadas. Partindo dessa premissa, lançamos mão da metodologia da história oral, que ganha espaço e vem desde então se consolidando como alternativa do fazer historiográfico, que, respaldada na história cultural, permite a apropriação de novos objetos e fontes. Afinal é através do processo rememorativo que os entrevistados se historisam e pelas suas vozes são autores de sua própria história. Portando, a metodologia da história oral nos permite atentar para as seguintes questões: Quem fala? Em que circunstancias se fala? Para quem se fala? 0 que se fala? Assim, recomenda Alberti:

\footnotetext{
[...] procurar compreender a sociedade através do indivíduo que nela viveu; de estabelecer relações entre o geral e o particular através da análise comparativa de diferentes testemunhos, e de tomar as formas como o passado é apreendido e interpretado por indivíduos e grupos como dado objetivo para compreender suas ações. (ALBERTI, 2005, p. 19)
} 
As entrevistas ${ }^{1}$, realizadas em Estância, nos dias 17 e 20 de Janeiro de 2012, nas residências das professoras: Rua Benjamin Constante, $n^{0} 26$ e Rua Gumercindo Bessa, $n^{0} 133$, tiveram o objetivo de mapear as trocas culturais que se operaram através da escola, vista aqui como objeto de estudo histórico. Para tanto, fez-se necessário uma análise das relações conflituosas e pacíficas, que se engendraram em diferentes tempos e espaços escolares. De fato, para entender as sinuosidades e entrelinhas que compõe a complexa malha da cultura escolar é preciso mergulhar nas fontes dos arquivos escolares, que embora escassas ou rebatidas pelo silêncio constituem-se em fragmentos que podem dizer muito.

Isto porque "[...] o historiador sabe fazer flechas com qualquer madeira" (JULIA, 2001, p.17). Uma vez que permitem, para além do que revelam os textos normativos, a compreensão de práticas culturais, resistências e tensões que emergem no funcionamento interno da escola, compondo uma espécie de "caixa preta", que ilustra o lócus das informações, que embora seja de difícil acesso, relevam as normas e finalidades que regem a escola, as práticas docentes de sala de aula, o papel de cada sujeito envolvido, bem como os conteúdos ensinados.

Assim, Julia define cultura escolar como: “[...] um conjunto de normas que definem conhecimentos a ensinar e condutas a inculcar, e um conjunto de práticas que permitem a transmissão desses conhecimentos e a incorporação desses comportamentos" (JULIA, 2001, p. 10-11). Ainda segundo ele, a cultura escolar se compõe por três elementos fundamentais que the dão estrutura: o espaço escolar específico, cursos graduados em níveis, bem como corpo profissional específico.

$1 \quad$ As entrevistas foram cedidas pelas professoras Eleonora Leite Pereira e Cordélia Nascimento Costa, a partir da Carta de Cessão de direitos, dispondo sobre os direitos e deveres do entrevistado, bem como o esclarecimento, sobre uso das entrevistas para fins de pesquisa acadêmica.
Parte-se dessas denotações sobre a composição da cultura escolar para refletir a respeito dos modos de ser e constituir-se professora e para tal fez-se necessário adentrar pelo conceito de "habitus Pedagógico”, pensado por Teive (2008). Vale ressaltar que a autora se valeu do conceito de habitus criado pelo sociólogo francês Pierre Bourdieu, como sendo um: "Sistema de disposições duráveis, estruturas estruturadas predispostas a funcionar como estruturas estruturantes, isto é, como principio gerador e estruturador de práticas e das representações." (BOURDIEU apud TEIVE, 2008, p 27). Ao pensar em tais denotações Teive concebe o habitus pedagógico da seguinte forma:

Habitus pedagógico, aqui é entendido, muito particularmente, como síntese do modo pelo qual o/a professora produz sentidos e formas de inteligibilidade acerca da educação escolarizada e, sobretudo, do modo que se age objetivamente no cotidiano escolar (TEIVE, 2008, p. 25).

Assim sendo, o habitus pedagógico se revela nas matrizes de percepções, de apreciações e de ações, a qual deverá orientar a ação quer planejada quer improvisada, do/a professor/a. Operar com essa categoria de análise nos proporcionou trilhar caminhos que nos levaram a compreender como nossas personagens se fizeram educadoras, para além do modo como interiorizaram os saberes selecionados no corpo de conhecimentos para suas composições biográficas, pois foi pelas disciplinares escolares apreendidas e experiências apropriadas em sala de aula que se tornaram professoras, uma vez que, a constituição destas se fez pelo trajeto percorrido na/pela educação, desde a sua mais tenra idade, por isso buscou-se em suas memórias escolares o cerne de sua formação, bem como a forma de pensar e agir o ensino escolarizado dentro do exercício pedagógico. 


\section{A REFORMA E A RESISTÊNCIA: CONTRIBUI- COÕES DOS REFORMADORES ANTÔNIO MANOEL DE CARVALHO NETO E HELVÉCIO FERREIRA DE ANDRADE}

Os ventos da modernidade traziam consigo os princípios de civilização, que pairavam sobre a nascente república brasileira, fortemente banhada pelos ideais de ordem e progresso, baseada na corrente do pensamento positivista. Assim, se importava o ideal de um "novo homem" e uma "nova sociedade", que deveriam estar em sintonia com o modelo econômico, social, político e educacional dos países da Europa. Tal empreendimento, de transformação da sociedade brasileira se operacionalizaria pelos projetos reformadores da Instrução Pública do inicio do século XX, prova disso é a publicação em 1882 do parecer proferido por Rui Barbosa, jurista, político e intelectual da educação.

Segundo Filho (2010), o conteúdo do parecer de Rui Barbosa identificou a ultrapassada rotina pedagógica, que se revelava pelo atraso a instrução pública, que por sua vez, sinalizava-se pelo alto índice de população esmagadoramente analfabeta. Para reverter tal quadro se fazia necessário à introdução de novos saberes, métodos, finalidades, para além de novas concepções ideológicas, que mudariam não só a realidade educacional, mas toda a sociedade. Para tanto o professor seria o principal responsável pelo sucesso da nova escola, pois para mudar o sistema de ensino, eram necessárias mudanças no fazer-se professor.

Aproximadamente meio século depois as ideias de Rui Barbosa desaguaram-se no pensamento escolanovista, iniciado na década de 1920, que dentre as suas principais proposições para o sistema de ensino ganha relevo a eficiência da escola, banhado pelo espirito cientifico, voltado à profissionalização, para além da bandeira de luta por uma educação gratuita, de qualidade, universal, obrigatória e laica.
O Manifesto dos Pioneiros da Educação Nova, publicado em 1932, pelos pensadores da educação Anísio Teixeira, Fernando de Azevedo e Lourenço Filho dentre outros, propuseram melhorias contundentes na educação brasileira. Segundo Vidal (2010) a Escola Nova empreenderia mudanças nos três eixos educacionais: primário normal, ensino técnico profissionalizante e no ensino secundário e superior, e dentre as suas principais medidas destacaram-se a renovação do material da escola, incorporação de novas tecnologias, bem como a formação para o trabalho. Contudo houve uma recusa da escola tradicional, que se caracterizava pelo professor como o centro das atividades, expositor dos conteúdos e detentor do conhecimento, em cujas práticas vigoravam o ensino verbalista e o processo de memorização dos alunos.

Assim, em contrapartida os pioneiros escolanovitas articularam um conjunto de medidas direcionadas para a edificação de um novo modelo de escola, cuja criança passaria para o centro do processo de aprendizagem, pois pela própria experiência, este construiria seu saber, sendo capacitado segundo as suas virtudes e vocações.

Mesmo com fisionomias diversificadas os ideais escolanovistas serviram de combustível ideólogo para os empreendimentos reformistas em todo o Brasil. Em Sergipe o processo de reforma da Instrução Pública ganha força com decreto $\mathrm{n}^{0} 867$ de 11 de março de 1924, durante a administração do então governador do Estado Maurício Graccho Cardoso.

Segundo o historiador Barreto (2002, p. 20), “Incorporando ao seu discurso o ideário do movimento da Escola Nova, Graccho Cardoso reconhece os avanços conquistados pelo Estado, nos últimos dez anos, mas faz duras crí- 
ticas à escola”. Assim, o Decreto 867, de 11 de março de 1924, proporcionou mudanças no Programa para o Curso Primário, Elementar e Superior, que se evidenciaram pela criação de escolas reunidas e grupos escolares, destinados a alunos de ambos os sexos, a criação de novos turnos, bem como, a garantia dos critérios de obrigatoriedade e gratuidade, dentre eles o de que os grupos escolares deveriam estar de acordo com as exigências de higiene escolar. Para tanto, foi imprescindível o papel do médico sergipano Helvécio Ferreira de Andrade.

Helvécio Ferreira de Andrade foi o introdutor das ideias escolanovistas em Sergipe. Diretor da Instrução Pública, no período entre 1913-1918, 1926-1927, 1930-1935 ele contribuiu com a difusão dos conceitos médico-higienistas, pois este entendia higiene e educação como sinônimos de progresso. Vislumbrava no método intuito, criado por Johann Heinrich Pestalozzi na Alemanha, um importante aliado para a reforma, uma vez que trazia as lições de coisas, estimulando os sentidos dos alunos. 0 que se pretendia, com o método, era que as lições se dariam pelas coisas, pelos olhos, pelos ouvidos, pelo tato, pelo cheiro, pelo gosto, enfim, aguçando percepções, intuições, observações e experimentações. Assim, despertava-se o senso investigativo e criador dos alunos que contava com novos processos de aplicação de leitura, escrita, recitação e exercícios. $\mathrm{Na}$ visão de Helvécio o método era visto da seguinte forma: "O ensino intuitivo é o que fala ao espírito e ao coração da criança por meio dos sentimentos” (ANDRADE apud VALENÇA, 2006, p. 182).

\section{NARRATIVAS DO VIVER NO COLÉGIO: REMEMORAÇ̃̃ES DO BÊ-Á-BÁ, DOS MÉTODOS, DOS MESTRES E EXAME.}

O Colégio Sagrado Coração de Jesus situado na Rua Gumercindo Bessa, no 271, no centro do município de Estância, foi fundado em 1 de março de
0 método intuitivo, propagandeado pela reforma educacional privilegiava a "pedagogia do ver" pela aquisição do conhecimento através dos sentidos. 0 fato é que para além das intenções da reforma, esta estaria sujeita às vontades, às práticas, e aos métodos já consolidados, uma vez que já estavam habituados ao modo de educar tradicional calcado na memorização, repetição, castigos e emulação.

Assim, foi, por certo, pela resistência das professoras, que a reforma educacional sofreu alterações e (des)ajustamentos em sua consolidação. 0 outro reformador sergipano que intercalou as ações com Helvécio de Andrade foi o bacharel em Direito Antônio Manuel de Carvalho-Neto, na visão de Lima (2006) a sua atuação contemplou: “Inspeção Médico-Escolar; Controle das Instituições Particulares de Ensino a fim de integrá-las nas Normas dos Modelos Oficiais de Ensino; Dotar a Escola Normal de materiais e laboratórios, com capacidade para desenvolver as Práticas de Ensino das Normalistas” (LIMA, 2006, p. 3225).

Antônio Manuel de Carvalho-Neto considerou a necessidade da presença periódica da inspeção escolar, bem como a cientificidade das disciplinas além de práticas higienistas e profiláticas, porém não se conseguia ajustar o sistema de ensino, pois segundo Valença (2006) a resistência à receptividade ao método intuito dos professores em Sergipe, não foi uma situação diferente em outros estados brasileiros, pois devido às práticas educativas e sociais já consolidadas no ser e fazer-se professora, uma vez que, estas acreditam no modo como foram ensinadas.
1936, por iniciativa do Cônego Antônio de Freitas, vigário da paróquia e do Juiz de direito Vicente Barreira de Alencar. Foi coordenado pelas irmãs Fran- 
ciscanas Hospitaleiras da Imaculada Conceição, se destacando às pioneiras: Dora da Santíssima Trindade, Maria das Chagas de São Francisco, Silvia de Maria Santíssima e Carmita de São José. Sobre os ensinamentos da professora Irmã Silvia de Maria Santíssima, nossa entrevistada professora Eleonora, lembra "ainda que estava no birô, quando a irmã mandava que eu lesse [...] e ela dizendo para mim [...] eu entendia como se juntava as sílabas[...] ficou assim marcada a minha alfabetização". E completa Cordélia: "as primeiras lições onde nos eram passados os conhecimento se faziam pelo tripé: ler, escrever e contar".

Ao desenrolar os fios das narrativas das professoras aqui estudadas, desvela-se uma cultura de escola e métodos de ensino próprios da educação no início do século XX. Segundo Vidal (2010) ainda pautadas em princípios pedagógicos tradicionais, o aluno se configurava sujeito passivo, um escoadouro de saberes que por sua vez se incorporavam de modo "quase que natural". Contrariando o que mandava a reforma, os modos de educar estavam eminentemente pautados no método sintético, que por sua vez se revela no aprendizado calcado na memorização, repetição, soletração quase que mecânica dos alunos, se constituindo uma "pedagogia do ouvir".

Segundo a professora Eleonora Leite o método de ensino "[...] era tudo na base de decorar. Tudo era para decorar. Eu tinha um professor que exigia que até as vírgulas estivessem no lugar. Ele botava assim... uma aluna no quadro, copiando o que ele ditava". Os saberes a serem ensinados no curso primário, ficam ainda registrados em sua fala: "[...] era na base de cópia e também dissertação. Era assim um quadro com figuras, e a gente olhava para aquele quadro e ia dizendo o que estava vendo. Falando daquilo". E acrescenta sobre os saberes: "tinha o famoso a, b, c .... a gente aprendia por ali. Tabuada e agente fazia a leitura. Leitura para ouvir e... lição... tomava a lição, ela chamava no birô. Tinha que ler uma por uma".
Entre os saberes a serem ensinados e condutas a serem inculcadas estavam imbricado os recursos e materiais didáticos que eram utilizados dentro do Colégio e mais objetivamente dentro da sala de aula: "[...] a gente estudava em uma pedra, não tinha caderno. Só que o lápis era o mesmo da pedra a gente escrevia e apagava com um matinho, chamado 'rabo de cavalo'... para apagar a letra".

Depois de concluir o ensino primário chegava a hora de prestar o exame de admissão e, "como um vestibular", causava ansiedade a toda a família das alunas que esperavam por uma aprovação. Uma vez que a educação secundária, segundo Silva (1969), significaria a fase do processo educativo que corresponde à adolescência que, a partir do ponto de vista pedagógico e curricular, atenderiam a necessidades especificas.

Vale ressaltar, que o Colégio Sagrado Coração de Jesus foi equiparado à Escola Normal Rui Barbosa, situada na capital aracajuana, desde 7 de Agosto de 1937, pelo decreto $n^{\circ} 88$. A respeito do exame de admissão, que era uma prática comum da época, a nossa entrevistada rememora: "Estudávamos pela Crestomatia para passar no exame de admissão [...] 0 exame de admissão era como um vestibular. A gente tinha muito medo, mas se não passasse pelo exame de admissão não entrava... Era escrito e oral também." O exame de admissão ao Ginásio era um processo seletivo, que selecionava pela aptidão intelectual dos alunos. Os Exames de Admissão ao Ginásio, vigentes de 1931 a 1971, complementavam a Reforma Francisco Campos, o Decreto ${ }^{\circ}$. 19.890 , de 18 de abril de 1931, estabelecia: "Art. 18 - 0 candidato à matrícula na $1^{\text {a }}$ série de estabelecimento de ensino secundário prestará exame de admissão na segunda quinzena de fevereiro". 


\section{DISCIPLINAS EDUCATIVAS, INSTRUTIVAS, PE- DAGÓGICAS: COMPONDO PROFESSORAS EM [DES] SINTONIA COM A REFORMA.}

Para compreender o fazer-se professora, bem como os saberes selecionados para sua composição, se fez necessário o dialogo com as obras do historiador da educação, André Chervel (1990). Segundo ele: "A história das disciplinas escolares não é então obrigada a cobrir a totalidade dos ensinos [...] os conteúdos é evidentemente seu componente central; o pivô ao redor do qual ela se constitui" (CHERVEL, 1990, p. 180). Dessa forma, entende-se que a composição das disciplinas em seus conteúdos de ensino não é uma construção ingênua nem tão pouco descomprometida, mas são pensadas e elaboradas em fina sintonia com finalidades e designações políticas, religiosas, econômicas, culturais e presididas pelas reformas educacionais, pois, estas estão direcionadas a formação do aluno pelo exercício intelectual em "idade escolar”, prova disso é a transformação dos ensinamentos de caráter disciplinar em científicos. Assim, pode-se conjecturar que as disciplinas são esses modos de transmissão cultural, que orquestra e dirigem aos alunos com finalidade e matrizes.

Para o entendimento das disciplinas como um conjunto acabado e com limites claramente traçados dos conteúdos escolares, deve-se levar em consideração que, para além dos saberes eleitos como indispensáveis em cada disciplina, as práticas docentes na sala de aula, o método utilizado, as condições materiais, a cultura que banha a escola, bem como a sociedade que a cerca traduzem as grandes finalidades que presidiram sua constituição.

Assim, não podem ser concebida descolada dos diversos elementos que the dão forma, presentes em cada tempo e espaço. 0 programa de disciplinas da Escola Normal do Colégio Sagrado Coração de Jesus em Estância eram compatíveis aos blocos de disciplinas da
Escola Normal Rui Barbosa em Aracaju, uma vez que estas eram equiparadas. As disciplinas contemplavam os saberes selecionados para a formação das normalistas em futuras educadoras, como bem conta professora Cordélia: "Sai de lá como professora".

Parafraseando Chervel (1990) as disciplinas são instrumentos que se apresentam como corpos de conhecimento, providos de uma lógica interna, articulados em torno de alguns temas específicos, organizados em planos sucessivos claramente diferenciados e que conduzem a finalidades. Para melhor, sistematização e entendimento de como se organizava os blocos das disciplinas, segue-se o modelo de divisão conforme Teive (2008) que classifica as disciplinas do curso normal em: "educativas", "instrutivas" e "pedagógicas”, conforme a nomenclatura usada na época.

Os conteúdos educativos, instrutivos e pedagógicos selecionados para a formação das professoras conduzem a objetivos e finalidades propostos pelas disciplinas. Assim, os marcos normativos do curso normal em Estância, contemplam os imperativos do nascente homem moderno, prático, urbano, bem como a sua orientação da sua vida em sociedade, banhado pelo cientificismo Comtiano em vigor na época. São as ciências que gradativamente passaram a serem escolarizadas. Isso explica a introdução de disciplinas instrutivas, como: Higiene, Aritmética, Física, Química, História Natural e Português.

Essas transformações curriculares implicavam em transformações metodológicas, pois com o método “intuitivo", pelo qual o aluno seria estimulado pelos sentidos, trazendo inovações no que tange ao uso de desenhos, estampas, gravuras, instigando a criatividade e o senso de investigação de curiosidade do alu- 
no, que entendia que a palavra existia para dar nome à coisa, isto pelo método de associações, "Pedagogia do olhar”. Porém, o vivido pelas professoras revelam particularidades que dão um novo sentido à cultura de escola do Colégio Sagrado Coração de Jesus, na década de 1940. Como narra Eleonora (2012):

\begin{abstract}
A Crestomatia tinha todas as matérias, inclusive poesia e histórias. Tinha tudo. Decorei essa Gramática inteirinha, Português eu era boa, tinha Literatura. Então minha queda sempre foi para Português, mas o ensino naquela época era o ditar. Abria o livro Irmã Silvia ditava e a gente copiava a matéria. [...] a aritmética na época era só somar, diminuir principalmente de multiplicar, dividir, máximo, mínimo a base mesmo da Matemática. [...] na história Natural, o autor era Acrisio Cruz. O professor era médico Dr. Jessé de Andrade Fontes. Ensinava o esqueleto humano todo, osso por osso. Eram os ossos todos, a gente sabia por nome a quantidade onde ficava, isso eu sabia, ele era medico então. Era isso que agente aprendia. A divisão do corpo humano, cabeça, tronco e membros, três partes cabeça, tronco e membros. (PEREIRA, 2012, p. ?)
\end{abstract}

As disciplinas educativas eleitas para compor o currículo, deveriam inculcar nas alunas o senso de pertencimento a pátria. Assim, estas desde cedo cultuariam em si e em seus futuros alunos o sentimento de amor à nação brasileira. Para isso as disciplinas de natureza educativa propagandeavam as ideias de unidade, coesão e solidariedade nacional, uma vez que seus conteúdos escolares louvam a pátria, o culto aos bons costumes e que se mostravam no ensino da História, Corográfica e Educação Moral, que, além de contemplarem os conteúdos de ensino histórico, protagonizadas pelas emblemáticas figuras nacionais, primava pelo ensino da noção de território brasileiro. 0 ufanismo e orgulho a nação brasileira deveriam estar na formação de caráter da futura professora. Para tal deveria acompanhar as lições de coisas representadas pelos mapas, globos terrestres, murais com gravuras, exposições cartográficas, viagens. Todavia não foram efetivados nos anos iniciais da reforma. Com base na cultura vivida, narra a professora Cordélia:

A Geografia era uma tortura, porque não se usava atlas, não se usava mapas. Era tanto que Norte, Sul, Leste, Oeste e a gente assim... Sem saber o que era
Norte o que era Sul. Sem saber o que era nada, então eu me lembro que eu detestava, que na minha época era Corográfica. Rio que separa, mas a gente sem noção real daquilo, então era difícil de guardar. [...] no curso Normal a Corográfia do Brasil e Gorográfia Geral agente estudava o continente todo. A Europa, a Azia e África. Em Historia do Brasil estudava desde a fundação o descobrimento, capitanias hereditárias e do Brasil e a Historia Geral é a Historia do mundo é tanta coisa.Tinha essa matéria também Educação Moral e Cívica. Era uma coisa assim que a gente ouvia para repetir, aprender mesmo os princípios de morais tudo isso era transmitido pela família à verdade é essa. Todas nós até hoje eu sei o Hino Nacional todo, e a gente achava que deveria ser obrigatório. Era a Bandeira $\mathrm{Na-}$ cional e o Hino Nacional agente cantava sempre antes da aula. (COSTA, 2012)

Em sintonia com o fio condutor, nos saberes educativos se posicionavam as disciplinas de Educação Física, Música (Canto Orfeônico), Trabalhos Manuais e Desenho. A disciplina de Educação Física foi formatada com o desígnio de proporcionar a valorização e cultivo de corpos saudáveis, ágeis e vigorosos, seguindo o propósito do modelo de vida civilizado nos centros urbanos, devendo conter exercícios que desenvolvessem o corpo e os músculos das alunas. As disciplinas de Desenho e Trabalhos Manuais, estavam direcionadas ao aprimoramento das prendas domestica, uma vez que estas eram preparadas para constituir uma família e um lar. Para tal, as disciplinas deveriam propiciar o bom funcionamento do sistema perceptivo das alunas, instigando sua capacidade de observação, tendo como principal objetivo fomentar sua imaginação, e como lembra a professora Eleonora, "deveríamos aprender ponto cruz, crochê de cor, tricô, bainha aberta para sermos preparadas para o lar”. A disciplina de Música (Canto Orfeônico) deveria contemplar os cantos e hinos de louvor a pátria e ao próprio colégio, que deveriam ser cantados em datas solenes. Como rememora as professoras:

\section{Música e Canto Orfeônico por Eleonora:}

O Canto Orfeônico ele ensinava as notas musicai. Extinguir pauta, clave e Dó, Ré, Mi todos os dias. Sem instrumentos era na base da prática, sem instrumentos. 
Aprendia e depois cantava, sem pauta sem nada, a professora cantava e agente ia atrás cantando também, 0 Hino do Colégio, o coral do colégio que tinha, no coral do colégio. Nas missas de domingo, tinha um igrejinha que ainda tem, nas formaturas, que tinha as formaturas de solene no próprio Colégio que agente cantava. (PEREIRA, 2012, p. ?) délia:

Hino do colégio Sagrado Coração de Jesus por Cor-

A fronte curvamos, humildes reverentes. A dirigir-te humílima oração. Nossa prece, atende complacente. Não nos deixe implorar-te em vão. Qual farol, seguro e luminoso. Existência a fora, nos conduz. E em busca de um reino glorioso. A ti seguimos, Coração de Jesus [...] esse Hino era muito cantado assim, nos feriados, nas festinhas. (COSTA, 2012, p. ?)

\section{A disciplina de desenho por Eleonora:}

Eram os retângulos, as figuras geométricas. As planas É isso mesmo cubo, cone é agente aprendia e desenhava aprendia desenhando. Usava os lápis coloridos, era em uma caixinha ainda me lembro assim com doze lápis. Era, era desse tamainho (mostrou com as mãos). Nós não tínhamos cera, nós tínhamos lápis de cor, o lápis que nós usamos como grafite só que colorido. (PEREIRA, 2012, p. ?).
Esse bloco de disciplina acima, se constituía em instrumentos de descanso e integralidade, uma vez que, tornavam os momentos em sala de aula mais suaves, proporcionando o descanso dos alunos em meio à fadiga da extenuante jornada das demais aulas, pois permitia um momento de descontração e leveza. Assim, o principal objetivo destas era captar a atenção das crianças, pois quando estivessem fadigadas passariam a cantar o hino do colégio, nas festas, missas e formaturas, bordar um enxoval, usar a criatividade com os lápis de cor nos desenhos ou até mesmo brincar com os times verde e vermelho.

As disciplinas de natureza instrutiva, educativa e pedagógica, se constituíam em um corpo de disciplinas que se articulavam entre si, com propósitos e desígnios traçados pelos reformadores, pois estes projetavam a construção de uma professora moderna, peça fundamental para o desenvolvimento da nação brasileira. Assim, se era e se fazia professora. Vale ressaltar que não foram encontradas, nas narrativas das professoras entrevistadas, lembranças da disciplina de Pedagogia.

\section{CONSIDERACÕ̃ES FINAIS}

Nas entrelinhas dos depoimentos orais das professoras Eleonora Leite Pereira e Cordélia do Nascimento Costa, desvelaram-se saberes, práticas sociais, modos de ser e fazer-se professora, tensionados e hibridizados entre os marcos normativos e culturas, pois, mesmo nossas personagens não tendo noção da reforma $n^{0} 867$ empreendida no estado, foram sujeitos partícipes dos seus desdobramentos. Uma vez que, para além dos propósitos reformistas as práticas culturais legitimadas socialmente, dentro das escolas se constituíam um ponto de confronto, entre reforma e resistência.
Assim, leva-se a acreditar que as contribuições dos reformadores: Antônio Manoel de Carvalho Neto e Helvécio Ferreira de Andrade atendiam as finalidades e designíos para a produção de um novo habitus pedagógico esperado das professoras primárias, pois os perfis biográficos aqui constituídos revelam-se na representatividade local que as entrevistadas possuem, visto que as organizações das narrativas de si, implicam colocar o sujeito em contato com suas experiências formadoras, as quais são perspectivadas a partir daquilo que cada um viveu e vive. Assim, conclui-se que perder-se e encontrar-se no labirinto 
das lembranças e esquecimentos das professoras, é nos deixar levar por caminhos que muito dizem da sua formação composta pelo trajeto percorrido na/pela educação em tempos e lugares.

\section{REFERÊNCIAS}

ALBERTI, Verena. Manual de história oral. Rio de Janeiro: FGV, 2005.

BARRETO, Luiz Antônio. Graccho Cardoso: Vida e Política. Aracaju: Instituto Tancredo Neves Aracaju - Sergipe, 2002.

COSTA, Cordélia do Nascimento. Relato oral sobre sua história de vida. Estância, 17 de Janeiro de 2012.

CHERVEL, André. História das disciplinas escolares: reflexão sobre um campo de pesquisa. Teoria e Educação. n. 2. 1990, p. 177-229.

FILHO, Luciano Mendes de Faria Filho. As retóricas das reformas. In. Reformas educacionais no Brasil: democratização qualidade da escola pública. Belo Horizonte: Mazza, 2010.

JULIA, D. A cultura escolar como objeto histórico. Revista Brasileira de História da Educação, Campinas, n. 1, p. 9-44, 2001.

LIMA, Maria do Socorro. "Carvalho Neto: a presença de um intelectual republicano nas reformas educacionais do estado de Sergipe”. In: VI- Congresso Luzo-Brasileiro de História da Educação. Minas, 2006.

PEREIRA, Eleonora Leite. Relato oral sobre sua história de vida. Estância, 20 de Janeiro de 2012.

SILVA, Geraldo Bastos. A Educação secundária: perspectiva histórica e teórica. São Paulo: Nacional. 1969.

TEIVE, Gladys Mary Ghizoni. “Uma vez normalista, sempre normalista”: Cultura Escolar e Produção de um habitus pedagógico- (Escola Normal Catarinense- 1911-1935) Florianópolis: Insular. 2008.

VALENÇA, Cristina de Almeida. Civilizar, Regenerar e Higienizar: a difusão da pedagogia moderna em Sergipe: a contribuição de Helvércio de Andrade (1913- 1935). São Cristóvão. UFS. 2006.

VALENTE, Wagner Rodrigues (Coord.). Os exames de admissão ao ginásio: 1931-1969. PUC/SP (Arquivos da Escola Estadual de São Paulo), CDs, 3 V., 2001.

VIDAL, Diana Gonçalves. Os Intelectuais e as Reformas. In: Reformas educacionais no Brasil: democratização e qualidade da escola pública. Belo Horizonte: Mazza. 2010. 

no bojo do projeto "guarda-chuva” intitulado "Memória Oral da Educação Sergipana" curso de Serviço Social/Unit, aluno de Iniciação Científica/ Programa Voluntário de Iniciação Científica-PROVIC, membro do Grupo de Pesquisa Sociedade, Educação, História e Memória- GPSEHM. E-mail: ronysocial@ hotmail.com. Pesquisa Sociedade, Educação, História e Memória- GPSEHM. E-mail: laisadias10@gmail.com. 